\title{
The Impact, Trend and Corporate Strategy of the FinTech Industry
}

\author{
Lei $\mathrm{Xu}$ \\ China Merchants Group Postdoctoral Research Station \\ Room 3008A, New Times Plaza, No.1 Taizi Road, Nanshan District, Shenzhen, China 518067 \\ Email: sppm.ie.thu@outlook.com
}

\begin{abstract}
This paper explores the impact FinTech is exerting on financial business, its future trend, and suitable strategies of market players based on a dataset of 892 global representative entrepreneurial firms and interviews to some of them. We find that FinTech will profoundly influence six business sections including assets management, payment and transfer, Internet lending and financing, retails bank, securities broker, and insurance. In the future, FinTech will transform current financial industry in six aspects: infrastructure, demand sources, service, forms of assets, operating principles, as well as market structure. The financial institutes should streamline the potentiality when applying FinTech to their businesses, and improve the capabilities of data analysis and application. Moreover, they may respond to FinTech by collaboration, development and the acquisition of entrepreneurial firms. FinTech firms should retain their customers with big data and high-quality service to ensure continuous value.
\end{abstract}

\section{Keywords-FinTech; Impact; Trend; Corporate Strategy}

\section{INTRODUCTION}

FinTech has always been the focus in financial world in recent years. It is a creative activity and format to remodel traditional financial products by creating and applying technology and serve and organize management. At present, financial industry is in the stage from internet to datamation and intellectualization, during which internet is used to supplement and replace traditional channels and a tide that data science and computing technology such as big data, cloud computing, artificial intelligence etc. are applied in financial field is formed. The tide abstracts more attention from financing institutions and capital all over the world. Therefore, a lot of entrepreneurial firms emerge and become major cusp of entrepreneurship at present. In 2012 to 2016, the accumulative financing amount of FinTech firms all over the world was nearly USD 40.6 billion, the financing amount and times showed a growth trend as a whole and total financing amount grew 5 times. In addition, average single financing amount also increased sharply, especially that the financing amount of China was leading all over the world in Asian area [1]. It is estimated that retails bank, payment and transfer, assets and wealth management, brokerage business etc. are those most likely shocked by FinTech. Before 2020, 28\% bank and payment transactions and $22 \%$ insurance and assets management services all over the world will be impacted greatly and the numbers of bank Employees and branches will be likely to sharply reduce by about $40 \%$ within 10 years [2]!

Under current development trend, which service fields will be impacted by FinTech industry? What is the development trend? What should traditional financing institutions do to reply FinTech revolution and what strategic measures should be taken by new FinTech firm? Focusing on the three questions, the paper discusses the development trend of FinTech industry.

Data of the paper is from three parts: firstly, Crunchbase database, which is one of the most important entrepreneurial firm databases in the world. Since the headquarters of main FinTech entrepreneurial firms are located in California, New York, London and China, the Author searched main business of the entrepreneurial firms in such places by taking as FinTech as the keyword at the end of March 2017 and screened top 10\% firms in popularity, 829 firms in total as the observation samples. Secondly, research reports of main consulting firms and think tanks internationally, such as CB Insights, PWC etc. Thirdly, depth interviews of the Author against many feathered FinTech firms in the United States.

\section{FINTECH IS EXERTING IMPACT ON FINANCIAL BUSINESS}

\section{A. Business field distribution of FinTech}

Since indications of Crunchbase database against main businesses of entrepreneurial firms are more fragmentary and have less systematicness than the classification of CB Insights, for the convenience of statistics, the Author firstly selects 128 representative firms reported by CB Insights from 892 firm samples and re-teases their main businesses by referring to FinTech industry classification of CB Insights [1]. CB Insights divides financial business as six aspects, i.e. assets management, payment and transfer, retails bank, internet lending and financing, securities broker and capital market and insurance. In addition, part entrepreneurial firms devote to technical services, such as network security technology, hardware technology, block chain technology etc. as the main businesses, which are not limited to the six business fields and extracted independently therefore.

Through teasing, the Author finds that main businesses of these representative FinTech enterprises are distributed in various business and technical fields in financial industry,

The research is sponsored by China Postdoctoral Science

Foundation (2017M612766) 
especially that the firms engaging in wealth management, payment and transfer and lending and financing (including $\mathrm{P} 2 \mathrm{P}$ credit, personal small-amount lending and financing and middle and small-sized enterprises credit) businesses are most (as shown in Figure 1). FinTech has profound impact on the six business fields.

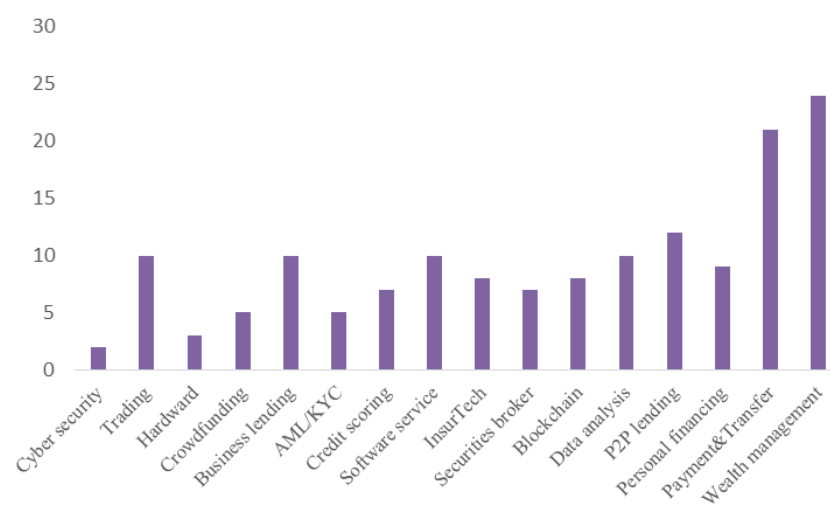

Fig. 1. Financial Business Field Distribution of Representative FinTech Firms

Data source: Crunchbase

(1) Assets management business: FinTech greatly expands the range of crowd served by assets management. Through mastering rich data of daily economic behaviors for customers, personal wealth management software is associated with offline scene naturally; by combining personal wealth management, C-terminal-oriented intelligent investment advisor develops rapidly and sinks customer group to common population, which meets current assets configuration demand of common population. However, the advancement and market acceptance of algorithm for domestic investment advisor still have difference with that in the United States and assets management field lacks relatively excellent transaction algorithm creation enterprises.

(2) Payment and transfer business: while Euramerican enterprises still innovate in hardware payment means, such as POS machine, credit card etc., China has entered in mobile internet payment system firstly. But innovation of Chinese enterprises in cross-border transfer tool is very insufficient. Block chain-based payment and transfer system will become an important branch in the future - especially in cross-border payment. Establishing business zoology centering on payment scene, obtaining and analyzing big data and pushing out new services in the future are necessary technical skills and the security and experience of payment means and the certification means (such as biological recognition, scanning etc.) are important technical barriers.

(3) Internet lending and financing business: at present, the bad debt rate of FinTech enterprise in such field is higher compared with that of traditional institutions and it is the core capacity of the enterprise to obtain multi-dimensional data to describe customer portrait to further keep risk management and personalized pricing. However, since the data network in China is in fragmentation status and the credit is still in initial stage, non-structured network data based on social contact, consumption etc. will become important data source of credit and it is of great importance to obtain non-structured data and have rational analysis model. For this, combination of online stream guidance and offline scene expansion is the way to obtain customers and to accumulate data.

(4) Retails bank business: similarly, the credit oriented to individual and small and micro enterprises highly depends on credit data and reliable analysis technology. At present, emerging network banks such as MYbank, WeBank etc. will construct strong risk management capacity and customer obtaining capacity based on big data source and analysis capacity, which will bring certain shock to traditional bank retails business. In addition, FinTech technology can also effectively improve anti-money laundering/fraud, post-loan monitoring and non-performing assets disposal capacity. What's more, block chain technology will revolutionarily reform supply chain finance of enterprise and note will become reliably circulated value carrier, for which individual commercial banks such as China Merchants Bank etc. have tested the prototype project.

(5) Securities broker and capital market: most domestic FinTech enterprises accumulate big data and expand commercial mode based on security brokerage platform However, the business range of the US enterprises is more diversified, which may be related to the development and management degree of capital market. Since scale economy and scope economy of diversified asset transactions are competitive advantages, the financing institutions should take full advantage of FinTech technology integration brokerage, quantitative investment, intelligent investment advisor, risk control etc. to cultivate steady ecological system.

(6) Insurance business: InsurTech emerges magnificently. Internet insurance has advantages of small amount service, high frequency and fragmented scene and can meet long-tail demand of long-tail customers, be applicable for standard simple products and reduce insured and claim costs. Therefore, many insurance firms begin to control risk and serve for customers based on technical basis of big data and artificial intelligence. In addition, it is the main development direction of InsurTech in the future that block chain is used to improve the efficiency and reliability of insuring, audit and claim settlement which is conductive to mutual insurance.

Moreover, the Author finds that main business of many firms among 892 firm samples is positioned to close combination of FinTech with various non-financial scene applications (as shown in Figure 2), such as advertising, commerce and shopping, sales and marketing etc. to seek the opportunity for permeation of FinTech in real economic scene, which further enriches commercial activities of real enterprises. 


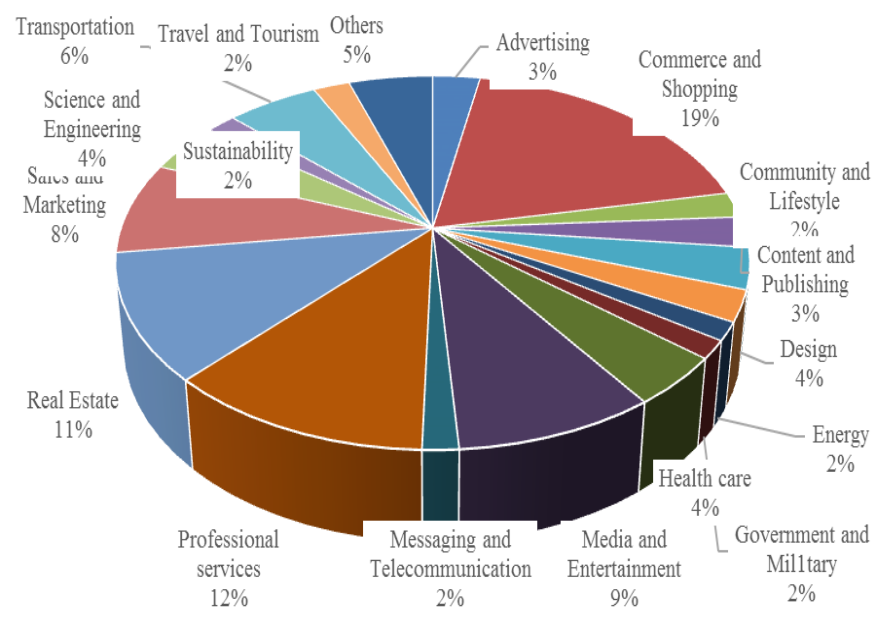

Fig. 2. Application Scene Proportion of FinTech Firms in Real Industry

Data source: Crunchbase

\section{B. Major emerging businesses: InsurTech and RegTech}

InsurTech and RegTech have been become two major emerging business fields of FinTech. InsurTech presents 7 businesses: firstly, mobile insurance management, which is that the consumers complete the management of insurance transactions and insurance schemes with mobile phones; secondly, online insurance agency service of small and micro enterprises, including professional liability insurance, mistake and omission insurance, general liability insurance etc.; thirdly, provide insurance and lost tracking for personal products such as mobile phone, computer etc.; fourthly, P2P insurance, i.e. establish the group with similar insurance demand with social network to share risk and economic burden; fifthly, establish online insurance intermediary of medical market, simplify traditional purchase process, pay attention to prevention and monitoring link and reduce user cost; sixthly, establish online price comparison platform on automobile market and develop UBI (user-based insurance) - i.e. collect data and observe driving behavior habits of users with intelligent equipment to further develop personalized insurance scheme and develop intelligent software allowing the users to upload damaged automobile pictures to simplify loss assessment and claim payment procedures of insurance firm by identifying pictures through artificial intelligence; seventhly, develop and design commercially intelligent software, database etc. for Insurers.

RegTech is the other important emerging branch. Although FinTech flourishes, financial innovation may conflict with laws. Appearance of RegTech is to solve the problem. After financial crisis, big banks pay big price for conformance to U.S. supervision laws and regulations with total penalty paid of USD 1.4 billion [3]. Meanwhile, supervisory governance of FinTech is accelerated all over the world [4]. In addition to the improvements based on laws and policies, RegTech attracts attention frequently. RegTech firms automatically analyze whether various services of customer firm are legal with new technology. What impacted by RegTech is not only conformance of financing institutions, but includes health care, bock chain, government, supply chain and logistics, information security, environmental protection etc. The business range includes enterprise risk management, tax management, anti-money laundering, customer identification, digital currency, operational risk management, transaction monitoring, report writing etc. Along with that financial stability and regulation importance were further emphasized on the $5^{\text {th }}$ National Conference on Financial Work in China and a Financial Stability Board of the State Council was established, RegTech will become an important FinTech development direction in future.

\section{TREND OF FINTECH INDUSTRY}

FinTech development in the future will present six important trends to further deeply change modern financial industry [5-6].

Firstly, infrastructure. Firstly, bottom communication network of financial system can turn from current telecommunication to the communication based on internet IP address so that the number of system nodes will increase greatly and the infusion of finance and internet will further deepen as well. Secondly, system architecture of the system will change from centralization to distribution and decentration and block chain will be the main bearing architecture in the future. Thirdly, the calculation and storage architecture of the system will turn from single and localized database at present to large-scale cloud terminal calculation and service.

Secondly, demand sources. Driven by mobile internet technology, big data technology etc., fragmented and scenarized service demands will emerge in large numbers, which means that service is required at any time and place and by any person. "Technology + scene" will constitute dual core to drive the development of financial service and diversified technical integration and diversified scene interconnection are of great importance. In addition, fragmentation also means that the service threshold of customer reduces greatly and everyone is a potential customer, which are conductive to promoting inclusive finance.

Thirdly, service. Financial service will turn from largescale and standardized public service to personalized accurate matching, which proposes very high requirement to the institution on the risk control capacity because that along with mining of many personalized customers, customer risk is not described by uniform probability distribution function any longer, but presents characteristics of long-tail and classification, which require respective processing. However, the measurability and control of such risks also improve due to rich big data technology.

Fourthly, forms of assets. Digital currency represented by Bitcoin and Ether is a new form of assets and has become a global financial topic. Along with that central banks introduce into digital currency technology, traditional finance operation rules will be changed profoundly. Combination of payment technology and digital currency will impel the realization of "cash-free society". In addition to digital currency, block chain, as infrastructure, can also make various assets which cannot be transacted currently on internet before show current interconnection value. For example, commercial bill may circulate freely among different persons. 
Fifthly, market structure. Multi-dimensional, large-scale and high-quality data will become one of the most important financial assets. In the future, while entrepreneurial firms will take root in subdivision field by virtue of unique FinTech, big firms will strive to make ecological platform and cooperate with entrepreneurial firms in vertical field for open innovation to further promote the emergence of business ecosystem.

Sixthly, operating principle. Operation of financial system does not depend on labor purely. Artificial intelligence will impel financial intellectualization rapidly and mobile internet and cloud computing technology will drive online financial service at any time, which cannot be completed by labor.

\section{StRATEGIC SUGGestions}

Both traditional financing institutions and FinTech firms trying to engage in financial business are making great effects to grasp the tide of FinTech industry and try to obtain new development bonus of financial industry, against which development of rational strategy is very important.

\section{A. Strategies of FinTech Firm}

Since new entrants will not only snatch resources of traditional financing institutions in stock customers, but also obtain incremental customers ignored and failed to be served by traditional financing institutions possibly, their key strategic points are to effectively use multi-dimensional and large-scale data and improve customer stickiness by focusing on highquality service to further continuously create value and form virtuous business system cycle (as shown in Figure 3 below). Next, the paper will explain the strategy by the case of an US InsurTech firm.

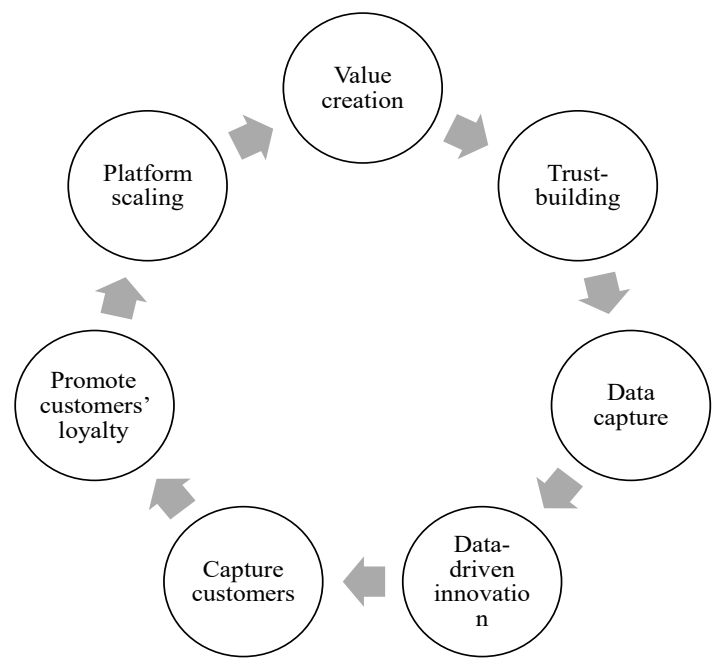

Fig. 3. Key Strategic Points of FinTech Firm

Founded in San Francisco in 2010, the US InsurTech Firm, CoverHound exists on the market as an insurance selling broker and cooperates with more than 40 insurance firms as an insurance price comparison platform to provide new and old insurances such as vehicle insurance, commercial insurance, housing insurance, network security insurance etc. CoverHound directly cooperates with insurance firms to ensure that the price is optimal. It proceeds from website design, APP development, product recommendation algorithm, customer questionnaire design etc. and pays attention to user experience. In addition, it also cooperates with traditional banks to achieve scene sales, after which the bank customers may select purchase of vehicle insurance, housing insurance etc. from CoverHound when handling vehicle loan and housing loan.

CoverHound is free for users and extracts commission from insurance firm. It carries out deep cooperation with Google. When the users search insurance products with google, CoverHound background has been in real-time information processing status. When users fill in insurance purchase information on the website, the background may also retrieve consumption behavior data from a third-party firm and recommend insurance products according to known consumption behavior for users after real-time processing. Only 3-4 most suitable insurance products will be displayed on home page of recommended results and can be resorted by the users voluntarily. CoverHound can recommend combination of insurances in different insurance firms for users and reserve maximum price discount simultaneously to achieve bundling sales. Estimated purchase price of the insurance can be completed within $3 \mathrm{~min}$ fastest and it takes $9 \mathrm{~min}$ to complete the whole purchase process on average. The whole purchase process can be completed once on the website without navigation to the page of insurance firm to restart payment process. In addition, the firm can also provide guidance for users during claim settlement process. By virtue of excellent customer experience, the firm can still complete customer growth by depending on recommendations of existing customers under limited advertisement budget. Figure 4 summaries the key strategic points of CoverHound.

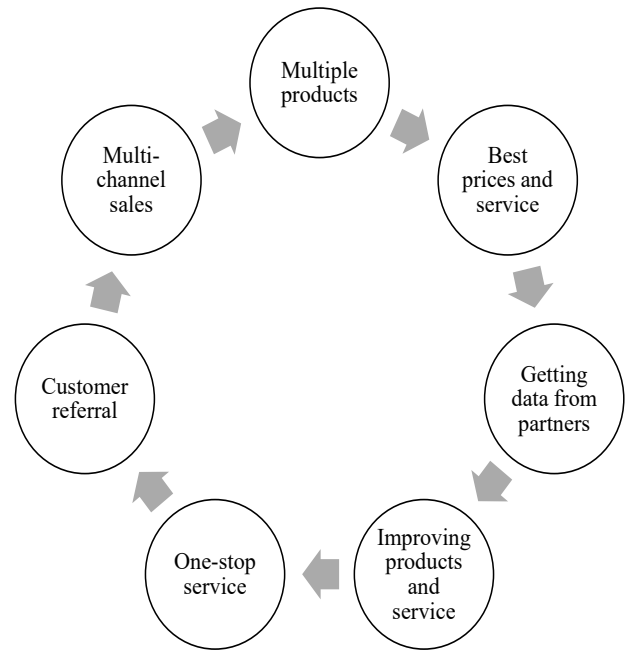

Fig. 4. Key Strategic Points of CoverHound

\section{B. Strategies of traditional financing institutions}

Since FinTech has great impact on business fields in financial industry, Reply to this revolution becomes a great challenge of traditional financing institutions. To reply to this challenge, traditional financing institutions should divide according to business type, deeply research the impacts of FinTech, possible business access points and cost benefit and 
potential risks of technical application and pay special attention to data analysis and application capacity.

Assets management institutions should actively integrate existing systems with digital solutions and improve research and analysis capacity to ensure that investment decisionmaking level is not behind in digital times. Retails bank should enhance risk control capacity based on big data and promote the development of inclusive finance with detailed risk control level and intelligent service system. Insurance firms should pay attention to accumulating multi-dimensional customer and scene data, improve product design, accurate marketing and online marking capacity in internet era and reduce customers' accident probability through additional services. Security brokerage firm should comprehensively promote information security guarantee and risk prediction levels, strengthen customer data collection and analysis, provide better additional services and adapt constantly updated technology, assets category and supervision policy [2].

Next, we will explain the replying strategy of traditional financing institutions through the case of Charles Schwab. Similarly located in San Francisco, Charles Schwab is one of the biggest financial management firms in the United States, with total assets of about USD 3,000 billion and main users of personal customer, registered investment advisor and enterprise. In personal customer, Charles Schwab has 1,200 financial advisors, providing more than 100,000 financing plans in total. Number of investment advisors serving for Charles Schwab ranks first in market share, accumulative service advisors exceed 7000, accumulative management assets exceed USD 13,500 billion and there are 1800 traders and operational support personnel employed. Charles Schwab has served for $1,500,000$ enterprise employees in total through enterprise pension plan. Over the past six years, the customer satisfaction for management of US pension plan has ranked first continuously with USD 100 billion pension being managed in total.

As an old-brand financing institution, Charles Schwab actively uses FinTech for transformation. The number of employees in Sci-tech Department reaches one third of total employees and departments have principals with high title and uniform internal management and clear labor division to achieve efficiency. Charles Schwab abandons traditional financial thinking, is led by customer demand and requires itself according to the standards of internet enterprise. For example, it independently researches and develops robot investment advisor to facilitate self-service process and save customers' time so that the customers generate dependency, initiatively reduces the charging standard of brokerage business and returns management fee of dissatisfied customers - these behaviors are unique in the industry. In addition, Charles Schwab also collects customer data through multiple channels and analyzes potential customer behavior habit with the data as marketing basis. In product link, Charles Schwab gets through bank and brokerage business platform as well to maximize group effect and the customers can complete transaction and handling of all financial products in single account through the platform.
In addition to strengthening connotative development of self-capability, traditional financing institutions may also look for excellent FinTech enterprises and mature enterprises both at home and abroad to seek for technical introduction and cooperation, or even strategic and financial investment to further achieve extended development. The first method is establishment of equity investment fund for direct equity investment or even acquisition of FinTech entrepreneurial firms to further obtain their financial product lines and hightechnology talents. For example, the biggest fund management firm all over the world, BlackRock acquires FutureAdvisor, an entrepreneurial firm focusing on intelligent investment advisor through negotiation and Citibank provides investment for a famous intelligent investment advisor firm, Betterment. The second method is cooperation with excellent FinTech enterprises in specific product and service, against which Zhongan Insurance is the example that traditional financial institution, Ping An Insurance cooperates with science and technology enterprises with advanced technology such as Ant Financial Services Group, Tencent etc. The third method is establishment of entrepreneurial incubation institution with strong anti-risk capability and sufficient capital to connect entrepreneurial firm and university laboratory to ensure selfcompetitiveness in the future form the origin [7].

Finally, since Internet lending and financing, personal credit information, equity-based crowdfunding are supervised more strictly, traditional financing institutions should pay attention to mastering the development of supervision policies and achieve conformance operation.

\section{CONCLUSION}

Through teasing of nearly 900 FinTech enterprises all over the world, the paper finds that current flourish development of FinTech industry not only has profound impact on six business divisions of assets management, payment and transfer, retails bank, Internet lending and financing, securities broker and capital market and insurance skilled by traditional financing institutions, but also combines closely with various nonfinancial scene applications. Flow introduction, scene imbedding, technical enabling, data feedback and business evolution form an organic closed-loop.

FinTech has major changes in infrastructure, demand sources, service, forms of assets, operating principle and competition structure. Therefore, the key strategic points of emerging FinTech Firms are to effectively use multidimensional and large-scale data and improve customer stickiness by focusing on high-quality service to further continuously create value. Traditional financing institutions should divide according to business type, deeply research the impacts of FinTech, possible business access points and cost benefit and potential risks of technical application and pay special attention to data analysis and application capacity 


\section{ACKNOWLEDGMENT}

The author appreciate the data collection work of $\mathrm{Mr}$. Taotao Zhang and Dr. Yi Yang as well as the suggestions from Dr. Baozhi Qu who are all staff of China Merchants Group. The paper is funded by China Postdoctoral Science Foundation (2017M612766).

\section{REFERENCES}

[1] CB Insights. The Global FinTech Report. 2016.

[2] PwC. Global FinTech Report. 2016.

[3] Arnold, M. Market grows for 'regtech', or AI for regulation. Financial Times, 2016-10-14.

[4] Liao Min, Current Situation and Future Trend of Global FinTech Supervision, New Finance, 2016(10):12-16.

[5] Enfodesk, Specific Analysis of China Financial Technology (FinTech). 2017

[6] Xiao Feng, Keynote Speech on "Global Sharing Finance 100 Forum • Xianghu Lake Summit http://www.sohu.com/a/130298311_617173.2017.

[7] BCG. Development Overview of FinTech in Insurance Industry Minutes of Telephone Meeting of Global Executive Management Committee. 2017. 